\title{
OBSERVATION AS A RESEARCH METHOD IN SOCIAL SCIENCE
}

\author{
Henryk DŹWIGOŁ ${ }^{1 *}$, Piotr BAROSZ ${ }^{2}$ \\ ${ }^{1}$ Silesian University of Technology, Faculty of Organisation and Management, Zabrze; \\ henryk.dzwigol@poczta.fm, ORCID: 0000-0002-2005-0078 \\ ${ }^{2}$ System Barosz Gwimet Sp. z o.o., 43-267 Suszec; piotr.barosz@barosz.pl, ORCID: 0000-0002-2984-4894 \\ * Correspondence author
}

Purpose: The aim of the article was to present the main ideas of observation viewed as one of the oldest research methods in social science.

Design/methodology/approach: As a result of the undertaken research process, 401 theoreticians of management science were surveyed.

Findings: Conclusions resulting from the conducted research clearly indicate that among the methods applied in practice for research in management science, based on observation of facts and classification used in the general methodology of inductive sciences, it is necessary to employ observations carried out in natural conditions and observations-interventions that take place as part of management activities in the surveyed entities.

Originality/value: Management science and methods should support business practice and, to some extent, provide guidance to executives and managers.

Keywords: observation, research methods, social science, research process.

\section{Introduction}

Under the conditions of the $21^{\text {st }}$ century the way businesses operate has been changing. An enterprise is no longer an organisation serving only its owners or shareholders. Modern businesses must be considered in the context of a wide range of stakeholders, which entails the necessity to weigh not only profit but also intangible assets: cultural, social, environmental, ethical, etc. In modern enterprises, the role of the boss (president, director, CEO) has also been changing dramatically. The said boss cannot be content with merely multiplying short-term profits regardless of their impact on the company's set of stakeholders (Dźwigol, 2018; Hair et al., 2019). These changes directly affect the need to diagnose the expectations of stakeholders and the business environment. 
Depending on the purpose of the undertaken research studies, we can, within the scope of cognitive practice, use qualitative research (Patton, 2002; Labraca, 2017) or quantitative research (Bryman, 2006; Park, and Park, 2016). These studies differ in numerous ways, however, the shortest way to define them is to state that quantitative studies are free from evaluation, whereas qualitative studies are influenced by the views of the researcher himself/herself (Almalki, 2016).

Qualitative research uses empiricism (Kesseba et al., 2018) and induction (Byrman, 2017), but also deduction (Kennedy, and Thornburg, 2018) in the process of formulating relationships between theories and concepts, and the reality. Qualitative methods include four main methods (techniques): observation, text and document analysis, interview, recording and transcription (Quinlan et al., 2019; Thomas, 2017). These methods are not isolated from each other; on the contrary, they are often combined, i.e. a blend of observation and interview (triangulation) (Joslin, and Müller, 2016; Hessen et al., 2019). It is also difficult to definitively and unequivocally separate qualitative and quantitative methods, and even the same methods acquire specific importance depending on the methodology applied (Vaivio, and Sirén, 2010).

Observations related to quantitative research are used to identify problems and are applied at the initial exploratory stage of research (Green, and Thorogood, 2018). As to qualitative research, observations become an essential method to recognize the phenomenon under investigation. Observation can be considered as one of the most universal and comprehensive techniques for collecting information (Noel et al., 2017). Therefore, and due to its complexity, there is a tendency to refer to it as a research method (Noel et al., 2018; Hair et al., 2019).

This trend cannot be considered appropriate, since observation is a central part of the cognitive methods, as it involves numerous ancillary techniques. It is therefore a comprehensive way of conducting research, which at the same time remains also the most fundamental, both by its history and its essence, when considered individually (Rheinhardt et al., 2018).

Observation is a research activity that collects information through observation (Green, and Thorogood, 2018). It is both a simple, spontaneous record of facts and events and a complex, controlled, systematic process of observation, through other auxiliary techniques, questionnaires, and by using the possibility of image and sound recording. Through observation, the researcher can obtain extremely 'natural' and real information about the surveyed community (Veal, 2017).

Observation is a method - systematic, purposeful and invisible - of perceiving the examined objects in their natural environment. According to one of the classifications, the following five types of observation were distinguished (Mintzberg, 2019):

- categorised observation - the researcher is equipped with a previously prepared scheme or questionnaire, and the observation of the phenomenon takes place based on data from these sheets,

- uncategorized observation - the researcher has not prepared a questionnaire or a scheme beforehand, so the observation is more free and spontaneous, 
- undisguised observation - the subjects know that they are being observed and examined, which may cause their unnatural behaviour and consequently bring about falsified information,

- participant observation - the researcher tries to penetrate the observed environment and conduct research from inside,

- direct - the investigator collects data and at the same time verifies its veracity using other test methods.

While characterising the observation, one cannot overlook the fact that it is a method strongly related to individual characteristics of observers (Hilgard, 2017), their research intuition, characteristic ability to explore the world or their biased vision of it. The problems that may arise from such cognition can be classified into the following three categories (Dźwigoł, 2018; Hair et al., 2019):

- imperfections in perception - since human senses have a limited range of perceiving stimuli,

- emotional attitude of the observer - very often the subject of the researcher's observation is a child, with whom he or she enters into numerous interpersonal contacts, has a fixed and well-established view of the pupil, so that he or she may lose the acuteness of his or her observations and only notice what confirms the opinion he or she has taken,

- cognitive stereotypes of the observer - they concern the ways phenomena are studied, facts and relationships are explained, etc.

Observation as a scientific method can be carried out in various ways giving the possibility of obtaining specific data about the examined phenomenon. It seems that a more useful method is disguised observation which enables a deeper understanding of the essence of the problem and the relations taking place in the studied environment. However, it requires from the researcher some special preparation and 'immunity' to various ethical and emotional circumstances that may arise in the research process.

\section{Research method}

Qualitative research methods found their use as empirical methods in the process of cognition and understanding of social phenomena, interactions taking place and defining social problems of the contemporary world. Qualitative methods make it possible to obtain empirical data, interpret and generalise them in social science, but also in management. The greatest potential, among the qualitative methods, in the context of obtaining source data and revealing the truth about social phenomena has observation and interview. The aim of the article is to present the main ideas of observation as one of the oldest research methods in social science. 
In view of the above, the article poses the following research questions:

Q1. Is it important to observe the research carried out in natural conditions, where the researcher interacts with the entities examined?

Q2. Are the observations-interventions that take place within the framework of management activities in the surveyed entities important, and does the researcher have a direct influence on the decisions taken?

Q3. Should cooperation between science and business practice have strategic character in the process of managing a modern enterprise?

Providing answers to the said research questions will allow to verify the following hypothesis: 'Among the methods used in practice for research in fact-based management science and the classification used in the general methodology of inductive science, two extremely important methods must be applied in research processes, namely:

a) observations carried out under natural conditions while the researcher interacts with the subjects examined,

b) the observations and interventions that take place as part of the management activities in the audited entities and the researcher has direct influence on the decisions taken.

In order to obtain answers to the research questions asked, the research was conducted using an anonymous questionnaire.

The survey was conducted in 2016-2018 by means of a questionnaire. It was prepared in two formats:

- in paper format, which was filled in during scientific conferences on management science,

- electronically, where the survey was sent to the addressees on the basis of an e-mail database.

The addressees of the survey were asked to answer 41 questions, the scope of which included:

- approach, processes and techniques and methods occurring in the research process (5 questions),

- quality problems in the research process (33 questions),

- demographics (3 questions).

While completing the questionnaire, the respondents answered both open, rank questions, and questions based on the 5-point Likert scale. Within the scope of the latter, the respondents were obliged to classify a particular answer as: strongly agree (5), agree (4), neither agree nor disagree (3), disagree (2), strongly disagree (1).

The analysis of the questionnaire surveys was based on 401 questionnaires. The subject included scientists from the management faculties of domestic and foreign universities. 


\section{Research results}

\subsection{Need to apply observation of research conducted in natural conditions where the researcher interacts with the subjects}

- $\mathrm{H}_{\mathrm{a}}$ - Among the methods practically used for research in management science based on fact observation and classification used in the general methodology of inductive sciences, it is necessary to use observations conducted in natural conditions while the researcher interacts with the subjects examined.

- $\mathrm{H}_{1 \mathrm{a}}$ - Among the methods practically used for research in management science based on fact observation and classification used in the general methodology of inductive science, it is not necessary to use observations carried out in natural conditions, while the researcher interacts with the subjects examined.

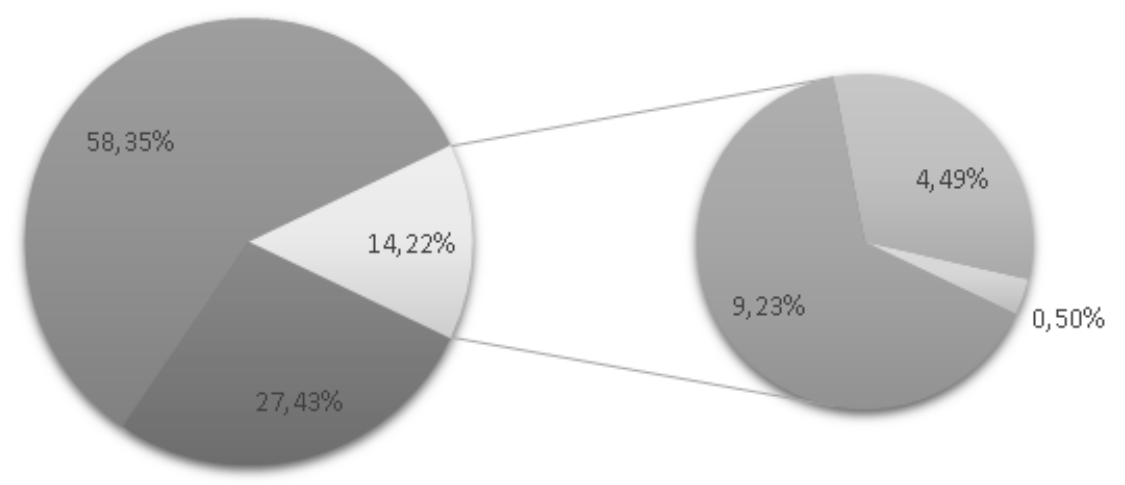

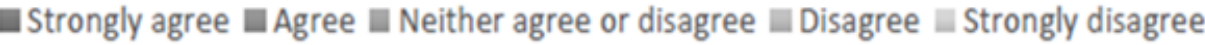

Figure 1. Research results: Q1. Is it important to observe the research conducted in natural conditions while the researcher interacts with the examined subjects? Authors' own research.

When analysing the results obtained, the vast majority of respondents $(85.78 \%)$ believe that it is important to observe the research conducted in natural conditions, while the researcher interacts with the examined entities, which at the same time allows to confirm the hypothesis.

\subsection{The need to apply in research processes the observations and interventions that take place as part of the management activities in the entities studied, while the researcher has a direct influence on the decisions taken}

- $\mathrm{H}_{\mathrm{b}}$ - Among the methods actually employed for research in management science based on the observation of facts and classification used in the general methodology of inductive science, it is necessary to apply observations and interventions that take place within the framework of management activities in the surveyed entities, while the researcher has a direct influence on decisions made. 
- $\mathrm{H}_{1 b}$ - Among the methods actually employed for research in management science based on the observation of facts and classification used in the general methodology of inductive science, it is not necessary to apply observations and interventions that take place within the framework of management activities in the surveyed entities, while the researcher has a direct influence on decisions made.

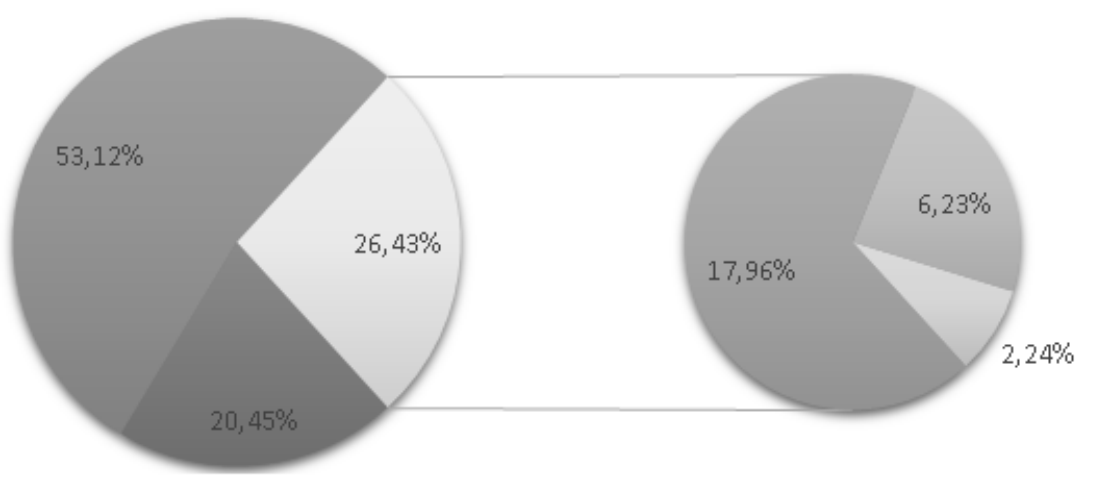

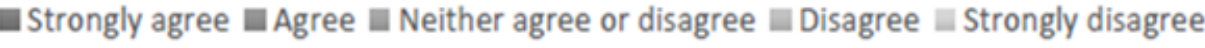

Figure 2. Test results: Q2. Are the observations-interventions, that take place within the framework of management activities in the surveyed entities, important, and does the researcher have a direct influence on the decisions made? Authors' own research.

When analysing the results obtained, the vast majority of respondents $(73.57 \%)$ believe that the observations-interventions that take place as part of management activities in the surveyed entities are important, and the researcher has a direct influence on the decisions made, which at the same time allows to confirm the hypothesis.

\subsection{Cooperation between science and business practice should be strategic in the process of managing a modern enterprise?}

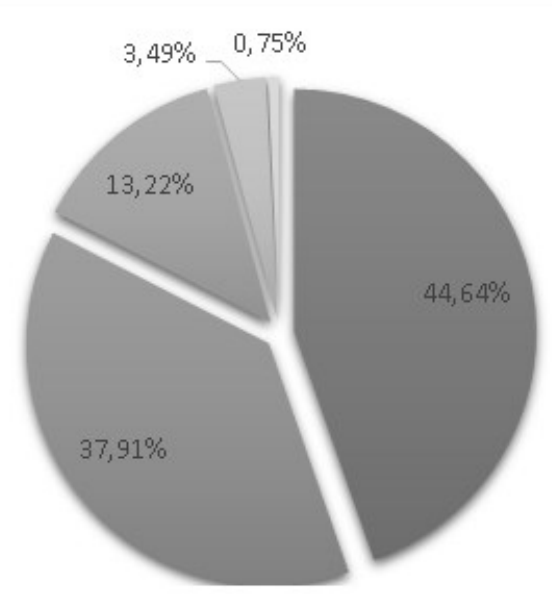

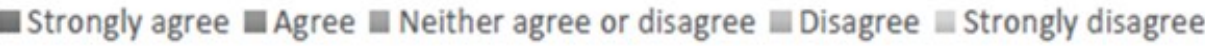

Figure 3. Research results: Should cooperation between science and business practice be of strategic character in the process of managing a modern enterprise? Authors' own research. 
There is a significant link between science and practice. This relationship arises from the fact that scientific research is always, or to a large extent, induced and conducted by the occurrence of a problem or phenomenon in the real world.

Theoretical sciences aim to get to know the natural and social world without asking how the research results will be used by humans in their activities. Practical research, on the other hand, is directed in advance to solve or describe a problem or phenomenon occurring in practice. Therefore, the practical layer must be accompanied by the theoretical layer and vice versa.

The mission of the management science is to provide knowledge and appropriate methods for studying problems within this discipline. The proper selection of methods for the analysed issues is a fundamental methodological issue. The foundations of science are not a set of laws or findings, but the process of creating accumulated knowledge (Joslin, and Müller, 2016).

\section{Summary and research conclusions}

The aim of the paper was to present the main ideas of observation viewed as one of the oldest research methods in social science. Conclusions resulting from the conducted research clearly indicate that:

- Among the methods practically used for research in fact-based management science and the classification applied in the general methodology of inductive science it is necessary to use:

o observations conducted in natural conditions, while the researcher cooperates with the subjects examined,

o observations and interventions that take place within the framework of management activities in the surveyed entities, and the researcher has a direct influence on the decisions taken.

- Cooperation between science and business practice should be of strategic character in the process of managing a modern enterprise.

Moreover, the organisational structure in modern enterprises is changing, which means abandoning bureaucratic and hierarchical forms, whereas the economic processes themselves run through so-called inter-organisational networks. Therefore, the concepts within which the so-called smart, virtual, organic (e.g. network- or cluster-like structure) and relational (Almalki, 2016; Boddy, 2016) organisations are built are of particular importance. In order to establish an organisation based on the above concepts, it is necessary to develop the organisation's resource, which is knowledge. Proper knowledge management will therefore be crucial for gaining a competitive advantage. 
Upon analysing the above solutions, it should be stated that management science and the methods used in it should support business practice and, to some extent, provide instructions to executives and managers. Management should be treated as a normative science, the aim of which is to formulate the principles of effective and efficient functioning of enterprises (Dźwigoł et al., 2019). Research results obtained during the research process in the field of management science should be applied in practice. Should this requirement be not met, management science shall be exposed to allegations of being science of lesser importance.

Qualitative research, thanks to the developed methods of collecting empirical data, allows for a deeper understanding of the surrounding social, organisational or even market reality. One of the basic qualitative methods can include observation, which enables the collection of empirical data and their subsequent analysis, creation of specific scientific categories of their properties and relationships among other categories.

\section{References}

1. Almalki, S. (2016). Integrating Quantitative and Qualitative Data in Mixed Methods Research—Challenges and Benefits. Journal of Education and Learning, 5(3), doi:10.5539/ jel.v5n3p288.

2. Boddy, C. (2016). Sample size for qualitative research. Qualitative Market Research, 19(4), 426-432. https://doi.org/10.1108/QMR-06-2016-0053.

3. Bryman, A. (2006). Integrating quantitative and qualitative research: How is it done? Qualitative Research, 6(1), 3-37, https://doi.org/10.1177/1468794106058877.

4. Bryman, A. (2017). Quantitative and qualitative research: further reflections on their integration. Mixing methods: Qualitative and quantitative research, 57-78, Routledge.

5. Dźwigoł, H. (2018). Współczesne procesy badawcze $w$ naukach o zarzadzaniu. Uwarunkowania metodyczne i metodologiczne. Warszawa: PWN.

6. Dzwigol, H., Aleinikova, O., Umanska, Y., Shmygol, N., \& Pushak, Y. (2019). An Entrepreneurship Model for Assessing the Investment Attractiveness of Regions. Journal of Entrepreneurship Education, 22(SI1), 1-7.

7. Green, J., \& Thorogood, N. (2018). Qualitative methods for health research. Sage.

8. Hair, J.F., Page, M., and Brunsveld, N. (2019). Essentials of Business Research Methods. New York: Routledge, https://doi.org/10.4324/9780429203374.

9. Hessen, R., Bright, L.K., and Zucker, A. (2019). Vindicating methodological triangulation. Synthese, 196(8), 3067-3081, https://doi.org/10.1007/s11229-016-1294-7.

10. Hilgard, E.R. (2017). Divided consciousness in hypnosis: The implications of the hidden observer. Hypnosis (pp. 45-80). Routledge. 
11. Joslin, R., and Müller, R. (2016). Identifying interesting project phenomena using philosophical and methodological triangulation. International Journal of Project Management, 34(6), 1043-1056, https://doi.org/10.1016/j.ijproman.2016.05.005.

12. Kennedy, B.L., \& Thornburg, R. (2018). Deduction, induction, and abduction, [in:] U. Flick (Ed.), The SAGE handbook of qualitative data collection (pp. 49-64). London: SAGE.

13. Kesseba, K., Awolowo, I., \& Clark, M. (2018). Qualitative research methodology: a neo-empiricist perspective. Driving productivity in uncertain and challenging times.

14. Labarca, C. (2017). Qualitative Research for beginners. Venezuela: Maracaibo.

15. Mintzberg, H. (2019). Structured observation as a method to study managerial work. Journal of.

16. Noel, A.B., Abdaoui, A., Elfouly, T., Ahmed, M.H., Badawy, A., \& Shehata, M.S. (2017). Structural health monitoring using wireless sensor networks: A comprehensive survey. IEEE Communications Surveys \& Tutorials, 19(3), 1403-1423.

17. Park, J. and Park, M. (2016). Qualitative versus Quantitative Research Methods: Discovery or Justification? Journal of Marketing Thought, 3(1), 1-7.

18. Patton, M.Q. (2002) Qualitative research and evaluation methods. Thousand Oaks: Sage Publications.

19. Quinlan, Ch., Babin, B., Carr, J., and Griffin, M. (2019). Business Research Methods. South Western Cengage.

20. Rheinhardt, A., Kreiner, G.E., Gioia, D.A., Corley, K.G., \& Cassell, C. (2018). Conducting and publishing rigorous qualitative research. Cassell C., Cunliffe AL, \& Grandy G. The Sage Handbook of Qualitative Business and Management Research Methods. Sage (Forthcoming).

21. Thomas, G. (2017). How to Do Your Research Project: A Guide for Students. London: Sage.

22. Vaivio, J., \& Sirén, A. (2010) Insights into method triangulation and "paradigms" in interpretive management accounting research. Management Accounting Research, 21(2), 130-141, https://doi.org/10.1016/j.mar.2010.03.001.

23. Veal, A.J. (2017). Research methods for leisure and tourism. UK: Pearson. 